University of Nebraska - Lincoln

DigitalCommons@University of Nebraska - Lincoln

Publications from USDA-ARS / UNL Faculty

U.S. Department of Agriculture: Agricultural

Research Service, Lincoln, Nebraska

2008

\title{
The Hawaii Fruit Fly Areawide Pest Management Programme
}

Roger I. Vargas

United States Department of Agriculture-Agricultural Research Service

Ronald F. L. Mau

University of Hawaii at Manoa

Eric B. Jang

United States Department of Agriculture- Agricultural Research Service, eric.jang@ars.usda.gov

Robert M. Faust

United States Department of Agriculture- Agricultural Research Service

Lyle Wong

Hawaii Department of Agriculture

Follow this and additional works at: https://digitalcommons.unl.edu/usdaarsfacpub

Part of the Agricultural Science Commons

Vargas, Roger I.; Mau, Ronald F. L.; Jang, Eric B.; Faust, Robert M.; and Wong, Lyle, "The Hawaii Fruit Fly Areawide Pest Management Programme" (2008). Publications from USDA-ARS / UNL Faculty. 656. https://digitalcommons.unl.edu/usdaarsfacpub/656

This Article is brought to you for free and open access by the U.S. Department of Agriculture: Agricultural Research Service, Lincoln, Nebraska at DigitalCommons@University of Nebraska - Lincoln. It has been accepted for inclusion in Publications from USDA-ARS / UNL Faculty by an authorized administrator of DigitalCommons@University of Nebraska - Lincoln. 


\title{
The Hawaii Fruit Fly Areawide Pest Management Programme
}

\author{
Roger I. VARGaS, ${ }^{1}$ RONALD F.L. MAU, ${ }^{2}$ ERIC B. JANG, ${ }^{1}$ \\ ROBERT M. FAUST ${ }^{3}$ AND LYLE WONG ${ }^{4}$ \\ 1 US Department of Agriculture, Agricultural Research Service, Pacific Basin \\ Agricultural Research Center, Hilo, Hawaii, USA \\ 2University of Hawaii at Manoa, College of Tropical Agriculture and Human \\ Resources, Department of Plant and Environmental Protection Sciences, \\ Gilmore, Honolulu, Hawaii, USA \\ ${ }^{3}$ US Department of Agriculture, Agricultural Research Service, Beltsville, \\ Maryland, USA \\ ${ }^{4}$ Hawaii Department of Agriculture, Division of Plant Industry, Honolulu, \\ Hawaii, USA
}

\section{Introduction}

\section{Description of the problem and need for an AWPM approach}

\section{Significance of the pest management problem}

Fruit flies (Diptera: Tephritidae) are among the most economically important pests attacking soft fruits worldwide (White and Elson-Harris, 1992). Four invasive species Mediterranean fruit fly or medfly (Ceratitis capitata), melon fly (Bactrocera cucurbitae), oriental fruit fly (Bactrocera dorsalis) and the so-called Malaysian fruit fly or solanaceous fruit fly (Bactrocera latifrons) - have been devastating to Hawaiian agriculture for over 100 years by infesting more than 400 different host plants. These fruit flies:

- Jeopardize development of a diversified tropical fruit and vegetable industry.

- Require that commercial fruits undergo quarantine treatment prior to export.

- Provide a breeding reservoir for their introduction into other parts of the world due to unprecedented travel and trade between countries.

Hawaii is not the only state in the USA troubled by fruit flies. Every year exotic fruit flies are accidentally introduced from various parts of the world into California and Florida. One species, the olive fruit fly (Bactrocera oleae), introduced into California in 1998, has become permanently established and has caused serious economic losses to olive growers (Yokoyama and Miller, 2004). Due to continuous introductions, current annual costs incurred in excluding medfly from California and Florida total over US $\$ 15$ million (http://www.cdfa.ca.gov). If the medfly became 
permanently established in California, projected losses would exceed US\$1 billion per year due to lost revenues, export treatment costs, trade and crop damage (Faust, 2004).

Bactrocera is a genus of 440 described species, widely distributed throughout tropical Asia, the south Pacific and Australia. Relatively few species exist in Africa, and only the olive fly, B. oleae, occurs in southern Europe (White and Elson-Harris, 1992). Recently, two species in the $B$. dorsalis complex became established on two new continents: $B$. carambolae, the carambola fruit fly, in South America (Suriname) and $B$. invadens in Africa (Kenya) (Drew et al., 2005; Rousse et al., 2005). The oriental fruit fly is found throughout Asia, including Bhutan, southern China, India and Thailand, and has been recorded from over 173 host plant species (White and Elson-Harris, 1992).

The oriental fruit fly was introduced into Hawaii in 1945 and is now the most abundant and widely distributed fruit fly in the islands. Studies suggest that $95 \%$ of the population develops in common guava, Psidium guajava and strawberry guava, $P$. cattleianum, and that population cycles are determined primarily by wild guava fruiting (Newell and Haramoto, 1968; Vargas et al., 1983). Commercial and backyard fruits are severely damaged by $B$. dorsalis population increases in nearby guava patches. Because of the abundance of common and strawberry guava throughout Hawaii, B. dorsalis has played a direct role in inhibiting the development of a profitable and diversified tropical fruit industry (Vargas et al., 2000).

The melon fly, the second most abundant and widely distributed fruit fly species in Hawaii, is a serious agricultural pest of cucurbits. It has been recorded from over 125 plant species (Weems, 1964) and is found in India, Myanmar, Malaysia, Thailand, the Philippines, southern China, Taiwan, East Africa, Guam, the Commonwealth of the Northern Mariana Islands, Papua New Guinea, Solomon Islands and the Hawaiian Islands (Nishida, 1953; White and Elson-Harris, 1992). In 1895 it was discovered in Hawaii (Back and Pemberton, 1917), where it causes serious economic damage to cultivated species of Cucurbitaceae (e.g. cucumber, Cucumis satizus; watermelon, Citrullus lanatus; cantaloupe, Cucumis melo; pumpkin, Cucurbita maxima; cultivated bitter melon (balsam pear), Momordica charantia; and courgette, Cucurbita pepo) (White and Elson-Harris, 1992). When populations are high and cucurbits scarce, B. cucurbitae also attack, with less frequency, other species of vegetables and fruits, such as papaya (Carica papaya).

Bactrocera latifrons is a less common dacine species, introduced about 1983 from South-east Asia. It is associated primarily with patches of wild and cultivated solanaceous fruits (Vargas and Nishida, 1985). Economic damage can be extensive in community gardens and farms where crops such as tomato (Solanum lycopersicon), aubergine (Solanum melogena) and pepper (Capsicum annuum) are cultivated (Vargas and Nishida, 1985).

Ceratitis is a genus of 65 species that originated in tropical and southern Africa (White and Elson-Harris, 1992). The medfly, C. capitata, was accidentally introduced into Hawaii from Australia in 1907, and it became a serious pest of tree fruits. When oriental fruit fly was introduced into Hawaii in 1945, it displaced medfly throughout most of its range, except in small patches with commercial and wild coffee (Coffea arabica), strawberry guava and a variety of upper-elevation fruits (i.e. peaches (Prunus persica), loquats (Eriobotrya japonica) and persimmons (Diospyros kaki)) (Vargas et al., 2001). 
In summary, fruit flies are both local and global pests, and areawide procedures developed in Hawaii have both local and worldwide applications.

\section{Description of current management systems and approaches}

In Hawaii, a transition from plantation agriculture to a more diversified agricultural economy has changed the diversity of crops grown and the size of farms. Instead of large monocultures such as sugarcane and pineapple, smaller plots with a variety of fruits and/or vegetables (even mixed crops on small acreage) are commonly planted. With few exceptions, independent farmers currently practise agriculture in Hawaii on small farms. Farming is a difficult and risky occupation due to the high cost of land, labour and equipment and the lack of an established marketing infrastructure for distribution of products.

For these reasons, farmers are reluctant to accept new pest control technologies unless they have been demonstrated to be successful and convenient. Growers are often unaware of crops grown on adjacent neighbours' land, and non-cultivated areas, where wild fruit fly host plants support breeding fruit fly populations. These areas are ideal breeding locations which, combined with the mild climatic conditions over much of the Hawaiian Islands, result in large population build-ups nearby, but outside cropping areas. Because of the natural tendency of fruit flies to disperse, the programme, as it expanded, included the whole range of producers, from backyard growers to community growers and on up to large commercial growers across the counties and islands, to make the programme a true areawide approach, as opposed to a farm-to-farm approach. None the less, with increases in the population of Hawaii and expansion of the tourist industry, the demand for fresh fruits and vegetables is greater than ever.

Overwhelmingly, pesticides have been the most popular control practices used against fruit flies. Calendar sprays are routinely used directly on crops to control fruit fly infestation. However, the heavy use of pesticides has been implicated in the reduction of natural enemies and, in some cases, secondary pest outbreaks. In addition, because of the non-traditional types and relatively small value of many crops grown in Hawaii, many pesticides are not registered for use on these crops. Use of non-registered pesticides and overuse of registered pesticides have renewed concerns regarding food safety and groundwater quality in many parts of the world. Because of the complexity of agroecosystems in Hawaii and the pest complexes that can occur on a given crop, areawide pest management (AWPM) approaches to fruit fly suppression were proposed as an alternative to the current practices.

\section{Limitations of current management approaches}

Fruit fly eradication programmes have been proposed for Hawaii on many occasions. However, demonstration eradication programmes against medfly conducted in Hawaii in the early 1990s identified several problems associated with the eradication technology available at that time. These included the high economic cost of large-area programmes, planting of large areas with coffee (the preferred host of medfly), lack of sufficient information on the effects upon non-target fauna, environmental concerns, quarantine issues and the lack of a large-scale sterile fly-rearing facility. 
Therefore, many scientists suggested that because environmental and economic costs of fruit fly eradication programmes were so high, emphasis should shift toward AWPM programmes and away from eradication. Although scientists in Hawaii have developed most of the technologies over the years to combat accidental fruit fly outbreaks on the US mainland (e.g. California and Florida), the technologies were never packaged and transferred to Hawaiian farmers. The Hawaii Areawide Pest Management programme was designed to transfer these technologies to Hawaiian farmers and residents.

\section{Anticipated benefits of AWPM}

The Hawaii AWPM programme was not aimed at eradication of fruit flies, but predicated on a pest management strategy that would reduce the entire population in and around cropping areas where economic damage occurred; or, at least, form part of a comprehensive business plan where potential pest problems (including fruit flies) were identified and factored into an economic cost-benefit analysis to facilitate production of fruits and vegetables for local consumption and export. It was envisioned that integration of new and old technologies into a pest management package would facilitate development of a well-defined agricultural production and marketing plan that would result in a better understanding of the potential of Hawaii agriculture in local, national and international markets. Furthermore, in the absence of eradication programmes in Hawaii, systems approaches using IPM methodologies may be one of the best strategies for reducing the environmental costs of continued high pesticide usage. These methods would also help in achieving quarantine security (Jang and Moffitt, 1994) while at the same time aid in producing higher-quality, safe fruits and vegetables for local consumption and possible niche export markets.

\section{Description of the AWPM Programme and Approaches}

\section{AWPM management technologies and approaches}

In 1999, the US Department of Agriculture (USDA), Agricultural Research Service (ARS) initiated the Hawaii Fruit Fly AWPM programme to suppress fruit flies below economic thresholds while reducing the use of organophosphate insecticides (Vargas et al., 2003b). The programme included developing and integrating biologically based pest technology into a comprehensive IPM package that was economically viable, environmentally friendly and sustainable. It included operational, research, education and assessment components. The technologies included (see Fig. 16.1):

- $\quad$ Field sanitation (Klungness et al., 2005).

- Application of protein bait sprays (Peck and McQuate, 2000; Vargas et al., 2001, 2002; Prokopy et al., 2004).

- Male and female annihilation with male lures and other attractants (Steiner et al., 1965; Koyama et al., 1984; Vargas et al., 2000, 2003a).

- Sterile insect releases (Steiner et al., 1970; McInnis et al., 1994; Vargas et al., 1994, 1995, 2004; Koyama, 1996). 


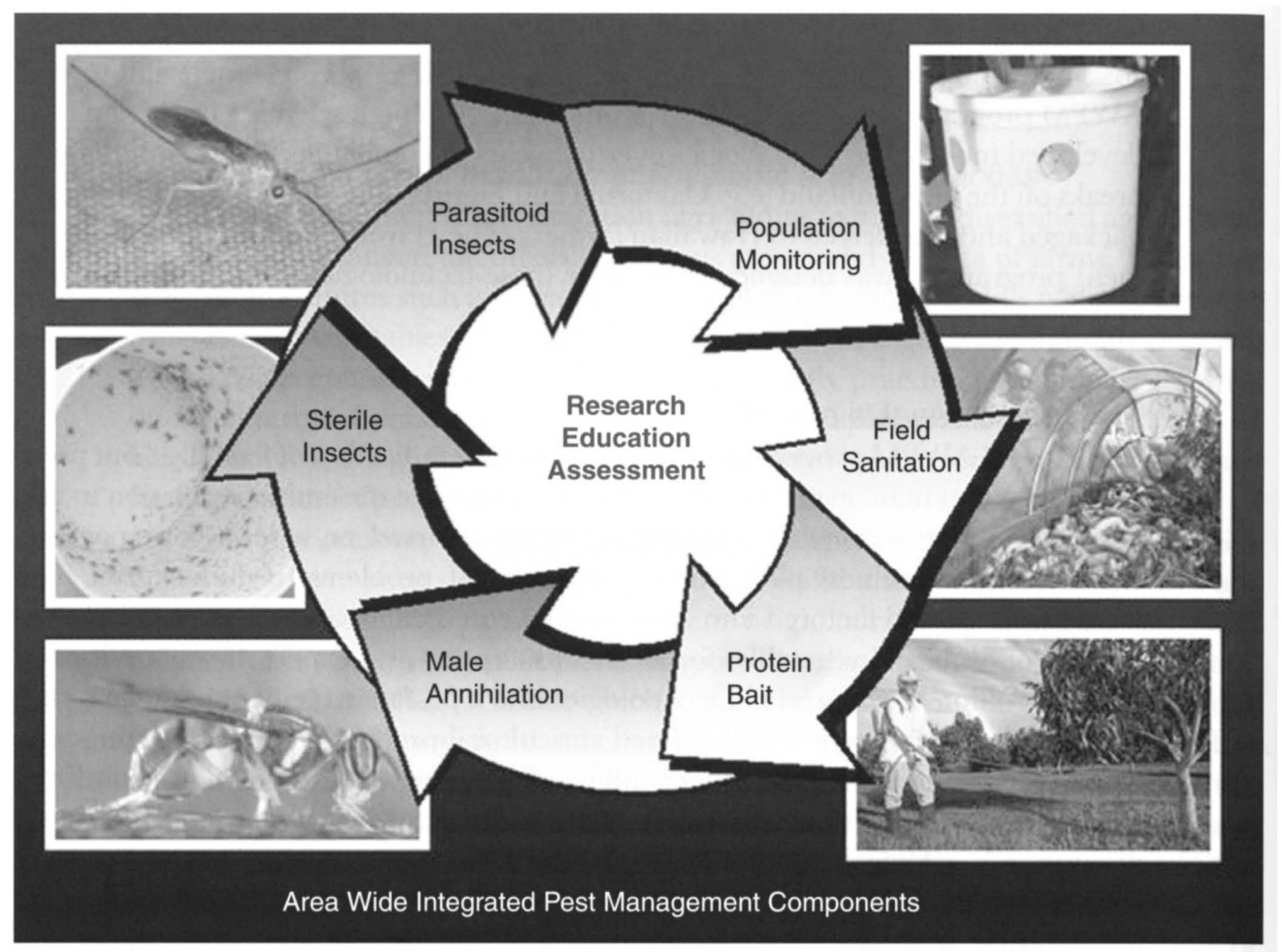

Fig. 16.1. The six components of the Hawaii AWPM prograrnme.

- Conservation or release of beneficial parasitoids (Wong et al., 1991, 1992; Purcell et al., 1994a, b; Knipling, 1995; Vargas et al., 2004, 2007a).

\section{Field sanitation}

Field sanitation is a technique that either prevents fruit fly larvae from developing or sequesters young emerging adult flies so that they cannot return to the crop to breed. In the past it was assumed that smashing fruits or rotor tilling the soil would kill most of the fruit fly larvae. However, preliminary tests demonstrated that only a small proportion of the flies were killed in this manner. Likewise, herbicide treatment of uncultivated host plants can stop plant growth, thereby reducing subsequent infestation of young fruit, but had little effect on larvae already developing in the fruit.

Consequently, the Hawaii AWPM programme promoted various methods of either killing the larvae in the fruit or preventing the larvae from developing into adult flies. Among the methods recommended by the programme were bagging or deep-burying infested fruit, drowning larvae in the fruit or sequestering emerging adult flies in tents or under plastic screens. Data suggest that larvae can go through window screens. However, if the screen is under the fruit, the larvae will crawl through it and pupate in the soil, but the emerging adults cannot escape back into the crop environment. Mechanization was recommended for some large farms. 
Grinding the fruit into fine pulp, thus macerating the larvae, is the surest method of destroying infested fruit, but may not be the most cost effective for small farms.

One novel sanitation device used in the programme was the augmentorium (Klungness et al., 2005). These tents, called augmentoria, were made with a screen material that restricted the dispersal of fruit fly adults emerging from the fruit placed in the tent, but allowed smaller fruit fly parasitoids that emerged from fruit culls to escape. Further details on methods of sanitation used in the Hawaii AWPM programme are to be found in Klungness et al. (2005).

\section{GF-120 Fruit Fly Bait spray}

Over the 50 years plus that organophosphate pesticides have been used to control fruit flies, they have been ineffective in the control of egg and larval development within the fruit (Keiser, 1968). Nishida and Bess (1950) recognized the inadequacy of spraying pesticide on the crop to control melon fly, because adult flies enter cultivated fields from surrounding areas to oviposit. Ebeling et al. (1953) suggested applying pesticides to maize borders surrounding the crop where flies congregate to invade the cultivated area. Nishida et al. (1957) then developed an effective technique for combining a food bait with a pesticide and applying it to border vegetation where flies roost.

Since their discovery, fruit flies have been controlled in agricultural areas of Hawaii using protein bait sprays. Most female flies need protein for full ovarian development and egg production, thus they readily feed on a protein source containing a toxicant. The bait spray strategy dramatically reduces the amount of pesticide needed for fruit fly control and has been used successfully in eradication campaigns (Steiner et al., 1961; Roessler, 1989).

Since the late 1950s, the most common toxicant used in fruit fly bait spray formulations has been the organophosphate insecticide, malathion (Roessler, 1989). $\mathrm{Nu}$-Lure has been the most popular protein bait mixed with malathion for fruit fly control (Prokopy et al., 1992). However, organophosphate insecticides have been implicated in negative effects on natural enemies and human health. Prior to the AWPM programme, new bait spray formulations containing reduced-risk insecticides, such as spinosad or phloxine B, were developed and tested for use in Central America and the USA (McQuate et al., 1999; Peck and McQuate, 2000).

Spinosad, a toxin derived from the soil-dwelling actinomycete bacterium, Saccharopolyspora spinosa Mertz and Yao, has low mammalian toxicity and reduced environmental impact on natural enemies (Stark et al., 2004). A hydrolysed protein bait with spinosad that attracted, induced feeding and killed fruit flies was initially developed by Moreno and Mangan (1995). The first bait contained liquid Mazoferm E802 $2^{\mathrm{TM}}$ (an enzymatically hydrolysed protein from maize processing; Corn Products, Argo, Illinois, USA) as the protein component. This bait was shown to have little impact against a series of beneficial hymenopteran parasitoids (Dowell, 1997) and reduced impact against honeybees (Dominguez et al., 2003). The Mazoferm bait was field tested against medfly in Hawaii (Peck and McQuate, 2000; Vargas et al., 2001).

A second bait, known as Solbait and composed of the protein attractant Solulys, a dried and more purified product processed from Mazoferm, was developed and successfully tested with a series of toxicants. Solbait has since been produced as GF-120 Fruit Fly Bait (Dow AgroSciences, Indianapolis, Indiana, USA) (DowElanco, 1994). 
Spinosad has extremely low vertebrate and environmental toxicity, with reduced risk to humans and wildlife when compared with traditional insecticides and is effective at much lower doses. It is effective against tephritids in doses as low as $1 \mathrm{ppm}$ in the laboratory. The low toxicity of spinosad towards beneficial insects allows it to be incorporated into many integrated pest management programmes that rely heavily on predators and parasitoids (Vargas et al., 2000, 2002).

The AWPM programme provided farmers with the new commercial formulation GF-120 Fruit Fly Bait as a substitute for Nu-Lure and malathion for control of fruit flies. This novel product, combined with sanitation in an IPM approach, became the major technology transfer to farmers participating in the Hawaii programme and provided the foundation from which the Hawaii AWPM programme grew. The initial successes of spinosad bait sprays were demonstrated with medfly (Peck and McQuate, 2000) and, subsequently, with melon fly (Prokopy et al., 2003). GF-120 was in the top group of proteins screened and generally rated higher than Nu-Lure, particularly when tested with protein-deprived flies (Vargas et al., 2002, 2007a; Prokopy et al., 2003; Vargas and Prokopy, 2007).

Aged baits, when compared with fresh baits, were unattractive to $B$. dorsalis and B. cucurbitae. Since attractiveness of bait droplets is short-lived, baits should be applied at short intervals or other ingredients added to baits to extend the period of attractiveness. Weekly applications of baits would probably be the shortest spray interval that is economically feasible for farmers.

\section{Male annihilation}

Worldwide, the Dacinae are astonishingly responsive to kairomone lures (Metcalf and Metcalf, 1992). At least $90 \%$ of the Dacinae species (comprising the two major genera Bactrocera and Dacus) are strongly attracted to either methyl eugenol (ME) or cue-lure (G-L/raspberry ketone) (Hardy, 1979). For instance, at least 176 species of the male Dacinae are attracted to $\mathrm{C}-\mathrm{L} /$ raspberry ketone, and 58 species to $\mathrm{ME}$ (Metcalf, 1990). Of the 73 Bactrocera and Dacus species that are agricultural pests, 41 respond to $\mathrm{C}-\mathrm{L} /$ raspberry ketone, 22 to $\mathrm{ME}$, and ten to neither (White and Elson-Harris, 1992).

Many tests have indicated that male annihilation (Steiner et al., 1970; Cunningham et al., 1975; Koyama et al., 1984; Cunningham and Suda, 1985, 1986; Vargas et al., 2000 ) is environmentally sound (Kido et al., 1996), cost effective and has excellent potential for areawide suppression of both melon fly and oriental fruit fly males. Vargas et al. (2000, 2003a) found that enclosing a wick inside bucket traps not only provided protection from the weather but also made the device visible, retrievable and reusable with limited environmental contamination.

However, in spite of being used in California for the last 25 years, and for many eradication programmes throughout the Pacific, male annihilation is still not legally available in Hawaii for control purposes, except on an experimental basis. Likewise, C-L has never been registered for control use in Hawaii. It was envisioned that development of simple, practical technologies for areawide use of ME and C-L would have important applications to suppression of fruit flies, not only in the Hawaii programme but also throughout the southern and western Pacific, Australia and tropical Asia, where Bactrocera are serious economic pests. Therefore, a special local needs permit was obtained for use of male annihilation in the AWPM programme. 
For the first time, the AWPM programme provided farmers and homeowners with male annihilation dispensers for control of oriental fruit fly and melon fly in Hawaii.

\section{Sterile insect technique}

Staff from ARS in Hawaii carried out the original pilot tests of the sterile insect technique (SIT) to eradicate oriental fruit fly in the western Pacific (Steiner et al., 1970) and to suppress or eradicate medfly in Hawaii (Harris et al., 1986) and California (Cunningham et al., 1980). In Japan, melon fly was eradicated by SIT (Koyama, 1996) using the Hawaiian approach. Subsequent SIT demonstration tests in Hawaii indicated significant reductions in fruit fly populations infesting large monocultures (Vargas et al., 1994, 1995; Vargas, 1996). However, the use of bisexual strains (males and females) precluded the application of SIT to fruit and vegetable farms with the AWPM programme where crops were susceptible to sting damage.

The potential advantages of an SI'T programme through the release of solely males not only included avoidance of 'sting-damage' by sterile females but also avoidance of matings between sterile males and sterile females. The effect of eliminating sterile females translated into increased efficiency of SIT by maximizing matings between sterile males and wild females. In the absence of sterile females, sterile males could find more wild female mates and improve the overall efficiency of an SIT programme (McInnis et al., 1994; Rendon et al., 2004). Development of males-only lines of melon fly and oriental fruit fly sexing strains allowed for the application of SIT to small-farm situations in the Hawaiian programme.

As part of the AWPM programme, a new strain of melon fly was developed and tested, which allowed for colour separation of males and females at the pupal stage through use of high-speed sorting machines. Known as the T-1 strain (McInnis et al., 2006), the resulting males were released in selected areas and significantly reduced the local melon fly population to near extinction. A similar strain was developed for the oriental fruit fly and evaluated in small-scale AWPM demonstration tests (McInnis et al., 2007). Although this approach proved very successful, the need for a large mass-rearing facility in Hawaii and more cost-effective 'sexing strains' limited its implementation.

\section{Fruit fly parasitoids}

The role of parasitoids in the Hawaiian AWPM fruit fly programmes was examined at three levels of application: (i) conservation; (ii) classical releases; and (iii) augmentative releases. An overall goal of the AWPM programme was to conserve biological control in economic crops through the use of reduced-risk insecticides such as GF-120 Fruit Fly Bait and male annihilation bucket traps, while using an AWPM approach (Vargas et al., 2001, 2003b; Prokopy et al., 2003; Stark et al., 2004). The programme succeeded in both reducing the use of organophosphates and conserving biological controls, such as Fopius arisanus and related braconid species, while suppressing fruit flies below economic injury levels.

Perhaps no fruit fly parasitoid has been as successful in suppressing host populations as $F$. arisanus (Rousse et al., 2005). Because of its habit of attacking host eggs, which are more exposed to parasitism than larvae, it can achieve high levels of parasitism, often surpassing 50\% in the field (Vargas et al., 1993, 2007a; Purcell et al., 1996). 
The success of classical biological control against fruit flies in Hawaii, in particular with $F$. arisanus, has been thoroughly reviewed by Rousse et al. (2005).

In Hawaii, the impact of $F$. arisanus introductions resulted in a $95 \%$ reduction in the oriental fruit fly population, from the 1947-1949 peak abundance of oriental fruit fly (DeBach and Rosen, 1991). Furthermore, F. arisanus became the major parasitoid of medfly in Hawaii (DeBach and Rosen, 1991; Vargas et al., 2001). Haramoto and Bess (1970) reported that the mean number of fruit fly pupae (oriental fruit fly and medfly) collected from coffee fruits in Kona, Hawaii decreased from 23.6 pupae per 100 fruits (8.7\% parasitism) in 1949 to 5.2 (66.6\% parasitism) in 1969. With this level of impact on infestation level, establishment of $F$. arisanus has reduced the threat of movement of fruit flies to the mainland from Hawaii.

Since $F$. arisanus was already established in Hawaii, it was not possible to test classical releases of parasitoids in Hawaii. However, just before the AWPM programme was initiated in Hawaii, oriental fruit fly became established in French Polynesia, the most likely source being Hawaii. As part of an AWPM and a Foreign Agricultural Service (FAS) initiative to extend the AWPM programme outside of Hawaii, F. arisanus was introduced into French Polynesia. During the project, fruit samples before and after releases of $F$. arisanus on Tahiti Island were compared. From 2002 (before parasitoid releases) to 2006 (after parasitoid releases), there was a decline in numbers of fruit flies emerging (per $\mathrm{kg}$ of fruit) for oriental fruit fly, Queensland fruit fly $($ B. tryon $)$ and B. kirki of $75.6,79.3$ and $97.9 \%$, respectively. It is recognized that much of the decline in numbers of Queensland fruit fly and B. kirki may have been due to competitive interactions with oriental fruit fly. However, $F$. arisanus probably also played a role in the decline.

French Polynesia consists of over 118 islands and atolls scattered over approximately $2,500,000 \mathrm{~km}^{2}$ of ocean. Currently, oriental fruit fly is confined to the Society Islands. Initially it was envisioned that $F$. arisanus could be mass reared at an estimated cost of US $\$ 2,000$ per 1,000,000 parasitoids (Harris et al., 2000) and transferred to other islands as oriental fruit fly spread throughout French Polynesia. However, when $F$. arisanus became numerous in fruits infested with oriental fruit fly on Tahiti Island, it became more cost-effective to recover wasps from fruits held inside screened cages and ship them to the outer islands than to mass rear them in the laboratory on artificial diets. This approach is now being used for shipments to islands where oriental fruit fly has spread in French Polynesia.

None the less, for approximately US $\$ 100,000$, the shipment and establishment of $F$. arisanus in French Polynesia has provided a sustainable programme to reduce the impact of oriental fruit fly, which was not obtained with much more expensive eradication programmes. Consequently, establishment of $F$. arisanus has reduced the threat of movement of fruit flies to new areas from French Polynesia. Finally, the present programme in French Polynesia has reduced damage by oriental fruit fly and developed a biological base for further development of IPM programmes in conjunction with sanitation, reduced-risk protein bait sprays and male annihilation treatments.

In Hawaii, augmentative release of parasitoids was selected as one of the major technologies to be transferred to farmers in the original project proposal. Numerous studies had demonstrated the feasibility of parasite augmentation to control fruit flies. In Hawaii, release of Diachasmimorpha tryoni (at $20,000 / \mathrm{km}^{2}$ per week over a $14 \mathrm{~km}^{2}$ area) more than tripled medfly parasitism rates (Wong et al., 1991). In studies with 
melon fly, augmentatively released Psytallia fletcheri significantly enhanced parasitism rates in vegetables (i.e. courgette and cucumber) compared with background populations in commercial fields (Purcell and Messing, 1996). Therefore, during the AWPM programme, $P$. fletcheri and $F$. arisanus were reared and released in wild cucurbit and guava patches, respectively, near agroecosystems (Vargas et al., 1993), with the objective of demonstrating a cost-effective, sustainable technology that could be integrated with bait sprays and male annihilation.

In releases of $P$. fletcheri against melon fly inside field cages, the numbers of melon flies emerging from fruits placed inside treatment cages were reduced up to 21 -fold and numbers of parasitoids were increased by 11 -fold (Vargas et al., 2004). In open-field releases of $P$. fletcheri into ivy gourd patches throughout the Kailua-Kona area, parasitism rates were increased 4.7 times in release plots compared with those in control plots. However, there was no significant $(P>0.05)$ reduction in emergence of flies from fruits. Similarly, in releases of $P$. fletcher in courgette plots in Waimea, there was an increase in parasitoid recovery rates; however, there was no reduction in melon fly damage (R.I. Vargas, Hilo, Hawaii, unpublished data). F. arisanus was also tested as an augmentative tool in small plots of guava in Waimea where the existing population of $F$. arisanus was low. Levels of parasitism were increased, but infestation was not reduced (R.I. Vargas, Hilo, Hawaii, unpublished data).

Although augmentative releases of parasitoids were shown to increase parasitism in the field, limited rearing capacity and high cost limited their level of implementation into a sustainable AWPM programme. On the other hand, classical biological control was demonstated to be very cost-effective and sustainable in the French Polynesian programme. Establishment of $F$. arisanus in French Polynesia against oriental fruit fly is now the most successful example of classical biological control of fruit flies in the Pacific area outside of the Hawaiian Islands, and serves as a model for introduction of the parasitoid into South America and Africa, where the carambola flies, B. carambolae and B. invadens (Drew et al., 2005), have recently become established. In addition, $F$. arisanus is being studied as a possible candidate for classical biological control of the peach fruit fly, B. zonata (Saunders), in Africa and in the Indian Ocean region (e.g. FAO/IAEA, 2005).

\section{Compatibility of the AWPM programme with crop management of co-occurring pests}

The use of environmentally friendly approaches for control of fruit flies created few problems for management of co-occurring pests and was generally compatible with other practices. Implementation of sanitation for fruit fly management also improved control of other pests. GF-120 Fruit Fly Bait received an all-crops label and GF-120 NF Naturalyte Fruit Fly Bait was approved for use in the production of certified organic fruits and vegetables. However, one major issue with the use of lures for male annihilation treatments was the perception that these treatments may be a threat to non-target organisms. Previous studies suggested that methyl eugenol was attractive to numerous non-target insects. However, more recently, in non-target studies of male annihilation funded by the AWPM programme, attraction to most non-targets was not to the male lures but, instead, to rotting insects in traps (Uchida et al., 2004, 2007; L. Leblanc, personal communication, Honolulu, Hawaii, February 2007). 


\section{Development and implementation of the AWPM programme}

In order to promote and implement the Hawaii AWPM programme, partnerships were created with representation from the federal, state and industrial sectors. These partners included: (i) the USDA (ARS and Agricultural Plant Health Inspection Service (APHIS)); (ii) the University of Hawaii (UH); (iii) the Hawaii Department of Agriculture (HDOA); and (iv) industry (Dow AgroSciences, Farmatech International, Scentry Biologicals, Better World Manufacturing and United Agricultural Products).

Industry provided the technologies (bait sprays, solid lures and traps), and ARS the initial research and development of these technologies. The UH Extension Service provided lists of stakeholders, potential cooperators, grower training, cooperative extension and community-based education on fruit fly issues. HDOA issued permits necessary to implement the new technologies. In addition to local partnerships, a management team and secondary technical advisory group was established to help guide the programme through its initial stages. Each year an annual review meeting was held to evaluate progress of the programme and recommend adjustments when necessary.

The four fruit fly pest species affected specific crops grown by different groups of small farmers, so it was necessary to implement the programme sequentially by pest species. Each species required a customized AWPM programme. The melon fly, the first species targeted, caused highest losses throughout the year to cucurbit, melon and solanaceous crops. These crops were commonly grown in small clusters of farms; medfly suppression was undertaken at the same time because of requests by fruit growers near the melon farmers. Medfly is a serious pest of persimmons grown at upper elevations, but the pest develops in uncultivated fruits that are found throughout the year. We were able to undertake medfly suppression at the same time as that for melon fly because of the enthusiastic assistance of persimmon growers on Maui and the support of the UH Extension Service.

Suppression demonstration programmes were implemented on three islands Hawaii, Maui and Oahu. At four sites different cropping systems were used to evaluate the various technologies proposed. The four major sites chosen to demonstrate fruit fly suppression technologies included Waimea (Hawaii Island), Kula (Maui Island), Kunia/Ewa (Oahu Island) and Puna (Hawaii Island). Melon fly and oriental fruit fly were the predominant species at all of the sites. Medfly occurred at low and moderate densities at Waimea and Kula, respectively; B. latifrons occurred in low numbers at each site.

The first demonstration project was initiated on Hawaii Island in the Waimea region. The 3800 ha demonstration zone (cucurbits and melons) was surrounded by pastures and characterized by homes and a small town that separated two farming areas. Melon fly was the principal species suppressed. The second implementation zone (4400 ha) (cucurbits, melons, tomatoes and persimmons) was at Kula on Maui Island. This zone was characterized by clusters of small farms (c. 7-10 ha) surrounded by wild fruit fly hosts. Melon fly, oriental fruit fly and medfly were the principal species controlled. Central Oahu was the third demonstration site; this area encompassed more than 1600 ha of farmland adjacent to large residential and industrial areas. Crops included watermelon, honeydew melon, cantaloupe, courgette, squash and pumpkin. Melon fly was the principal species suppressed. The fourth implementation 
zone was at Puna, where the programme was applied to approximately 400 ha of papaya orchards. The cultivated area was surrounded by dense stands of uncultivated strawberry and common guava and fruit trees that sustained a very large oriental fruit fly population.

Suppression of oriental fruit fly in papaya orchards proved very challenging. The sequence of sites selected as the programme progressed turned out to be fortuitous and added to the credibility of the eventual success of the programme. The success of the melon fly control programme, and subsequently the medfly programme, allowed for development of an oriental fruit fly programme in areas of high infestation such as Puna. Development of the programme to suppress oriental fruit fly, application of the programme to Puna and registration of the necessary chemicals required an extension of 3 additional years. Expansion of the programme beyond the original demonstration sites is discussed under the prospects for sustainability section.

\section{Development and implementation of education and technology transfer programmes}

Previous IPM pilot tests in Hawaii had shown potential for local applications, but had never been partnered with a good extension programme. The critical ingredient to the success of the Hawaii AWPM programme was an organized, coordinated and comprehensive outreach educational programme. The Hawaii AWPM programme used the 'logic model' approach to organize, plan, execute and evaluate farmer and community educational programmes state-wide (Mau et al., 2007). The logic model approach was an outcome-driven rather than activity-based method that used a linear sequence that developed relationships between programme inputs, outputs and outcomes.

A 5-year outreach education plan was devised (Mau et al., 2003a). One of the most important outcomes was development of empowered participants who could make informed decisions based on retained knowledge and skills. This effective transfer of knowledge and skills helped to assure sustainability of the AWPM programme. Four important types of outputs were established early in the educational programme. The AWPM video provided an overview of the suppression programme in lay terms for commercial and community cooperators (Mau et al., 2003b). This video is shown frequently on public access television.

A series of brochures that described the suppression programme, identification and life cycle of the four targeted species of fruit flies and suppression elements were developed soon thereafter. The brochures included photographs and described in lay terms the importance of species monitoring, crop sanitation, male lures, male annihilation, protein baits and biological control. An Internet web site was created to provide ready access to information and updates (http://www.fruitfly. hawaii.edu).

A newsletter was established and published monthly for cooperators and partners who did not have Internet access. Other teaching materials were created and distributed when they were needed. The extension service marketed fruit fly suppression to farmers in the format of: 'As easy as 1 (population monitoring), 2 (sanitation), 3 (protein baits), 4 (male annihilation)'. This fruit fly programme became known as 
the '1-2-3-4 programme'. More details on the extension and education programme are to be found in Mau et al. (2007).

\section{Evaluation of the AWPM Programme}

\section{Effectiveness of the AWPM programme at controlling target pests}

The effectiveness of the AWPM programme was determined primarily on the basis of lower fruit fly trap captures, reduction in fruit infestation and reduction in organophosphate pesticide use. Depicted in Figs 16.2, 16.3 and 16.4 are the impact on trap captures through implementation of the different programme components against melon fly, medfly and oriental fruit fly at three different demonstration sites located at Waimea, Kula and Puna, respectively.

At Waimea on Hawaii Island, implementation of sanitation reduced captures of melon flies at managed farms to approximately one melon fly/trap/day. Subsequent implementation of GF-120 Fruit Fly Bait sprays, male annihilation (cue-lure traps), sterile flies and parasitoids reduced the melon fly population to nearly zero at treated farms. At Kula on Maui Island, implementation of Biolure traps and GF-120 Fruit Fly Bait sprays reduced captures of medflies to fewer than 0.1 flies/trap/day. At Puna on Hawaii Island, implementation of a combination of sanitation, male annihilation traps and GF-120 sprays reduced captures of oriental fruit fly by tenfold in treated papaya orchard traps when compared with untreated control area traps.

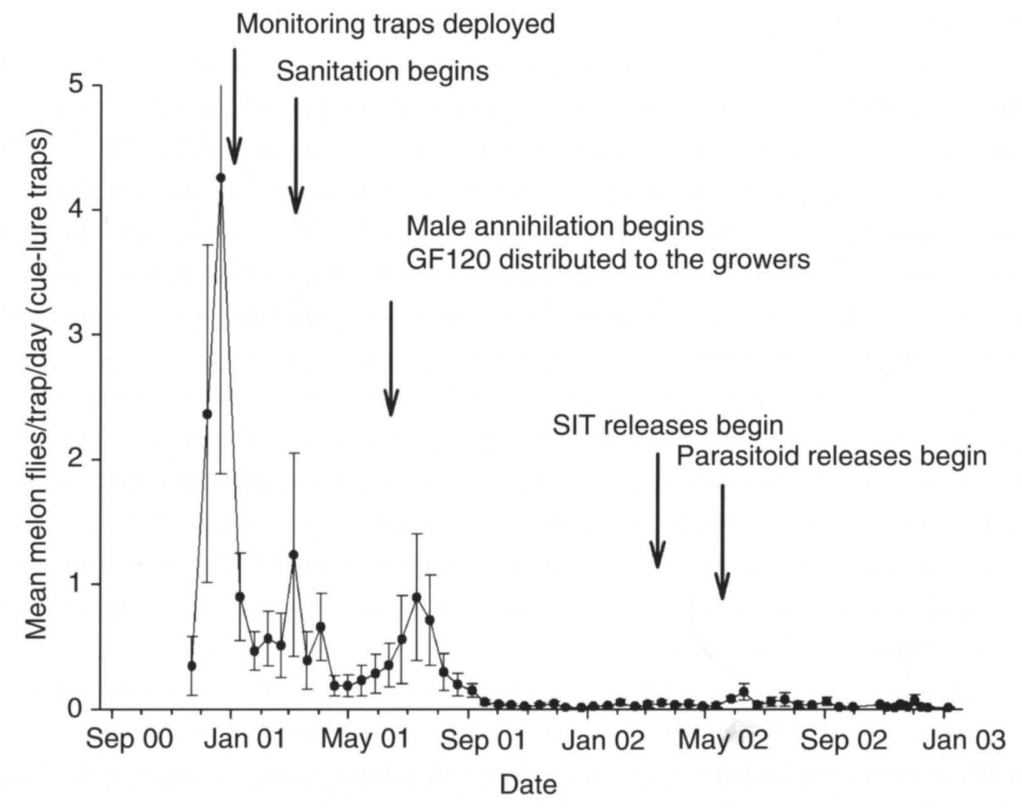

Fig. 16.2. Captures of melon flies on AWPM farrns at Waimea, Hawaii Island, Hawaii. 


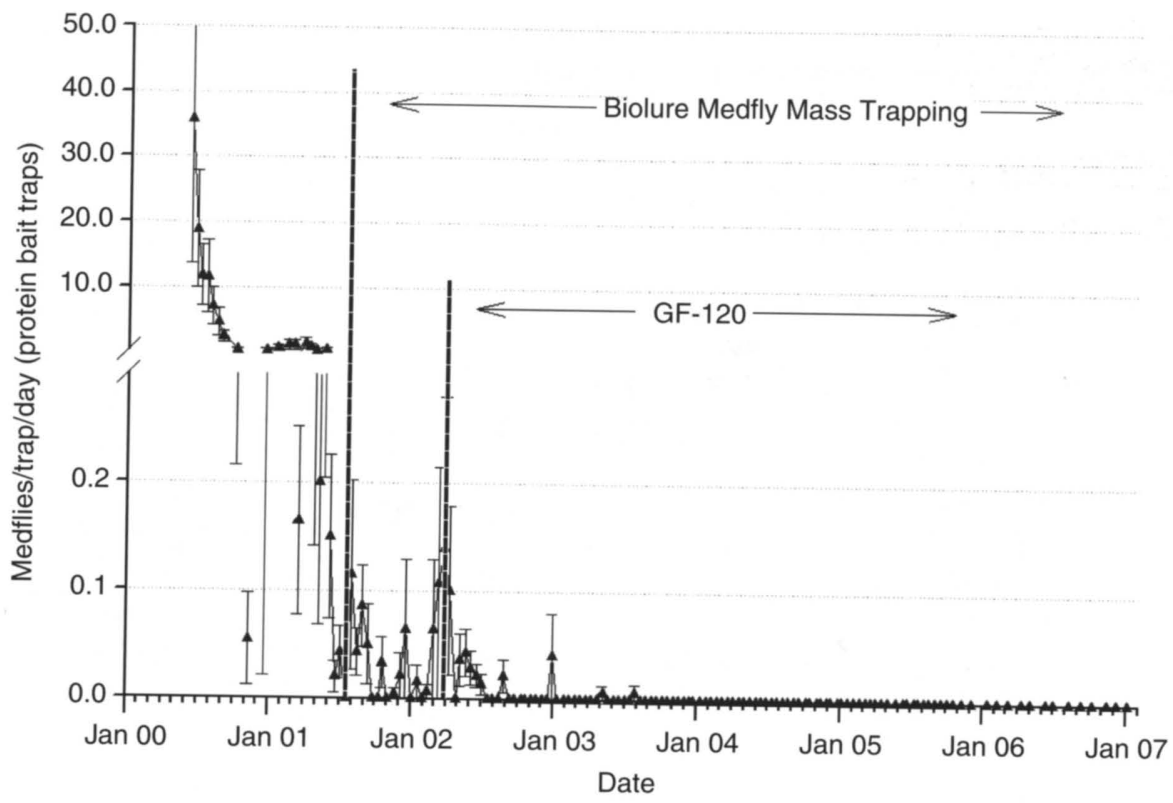

Fig. 16.3. Captures of medflies on AWPM farms at Kula, Maui Island, Hawaii.

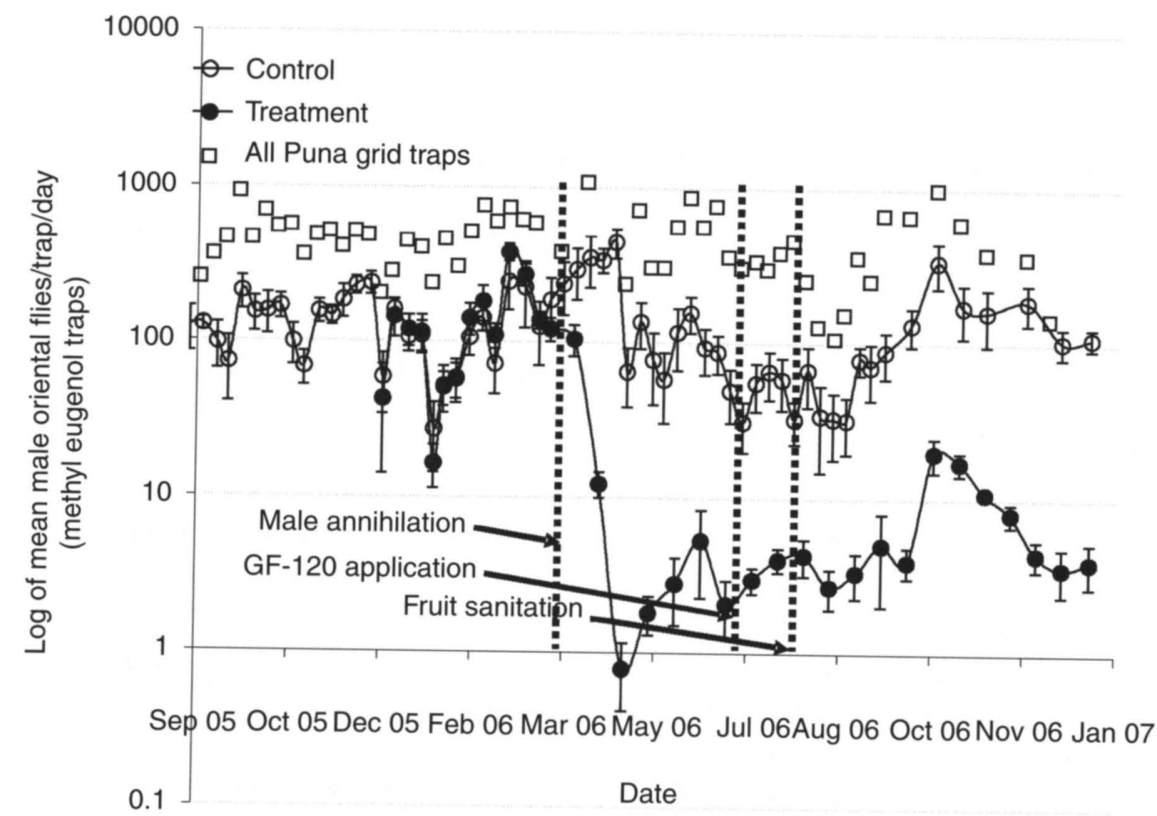

Fig. 16.4. Captures (log scale) of oriental fruit flies at Puna, Hawaii Island, Hawaii, in AWPM orchard traps, control traps and survey traps, with the sequential application of male annihilation, GF-120 fruit fly bait and sanitation. 
Table 16.1. Papaya fruit infestation sampled from treated and non-treated orchards by stage of ripeness for oriental fruit fly.

\begin{tabular}{lccccc}
\hline Ripeness index & $n$ & $\begin{array}{r}\text { Infested } \\
\text { fruit }(n)\end{array}$ & $\begin{array}{r}\text { Infested } \\
\text { fruit (\%) }\end{array}$ & $\begin{array}{c}\text { Mean } \\
\text { flies/g }\end{array}$ & SEM \\
\hline AWPM treatment & & & & & \\
site & 84 & 0 & 0.00 & 0.0000 & 0.0000 \\
$\quad$ Colour break & 84 & 0 & 0.00 & 0.0000 & 0.0000 \\
$1 / 4$ ripe & 82 & 2 & 2.44 & 0.0022 & 0.0018 \\
$\quad 1 / 2$ ripe & 82 & 7 & 8.54 & 0.0014 & 0.0067 \\
Fully ripe & & & & & \\
Control site & 90 & 0 & 0.00 & 0.0000 & 0.0000 \\
Colour break & 90 & 0 & 0.00 & 0.0000 & 0.0000 \\
$\quad 1 / 4$ ripe & 86 & 3 & 3.49 & 0.0005 & 0.0003 \\
$1 / 2$ ripe & 83 & 20 & 24.39 & 0.0245 & 0.0069 \\
$\quad$ Fully ripe & & & & & \\
\hline
\end{tabular}

Comparison of papaya fruit infestation sampled from treated orchards with those from non-treated orchards suggests that riper papaya fruits could be marketed from treated fields, providing higher-quality fruit for local consumption (see Table 16.1). The potential impact of these preharvest suppression measures on quarantine regulations for export of papaya fruit because of reduced infestation is presently being examined.

\section{Unintended negative and positive consequences of the AWPM programme}

The major positive feature of the AWPM programme was the close and effective collaboration between the various AWPM lead agencies in Hawaii. The programme's close collaboration is being considered as a template for future agricultural research and technology transfer programmes in Hawaii (Jang, 2003). Furthermore, California and Florida have also shown a keen interest in the programme. California alone would suffer a US $\$ 1.5$ billion annual loss in export sanctions, treatment costs, lost markets and reduced crop yields if the medfly became established there. Development and application of environmentally friendly areawide fruit fly controls, as performed in the Hawaiian AWPM programme, are of critical importance in keeping the US mainland free of the fruit flies already established in Hawaii.

Finally, unique to the Hawaiian AWPM programme has been development of international collaborations. There have been close interactions with officials and researchers from many other countries, including Taiwan, the People's Republic of China (PRC), Australia, French Polynesia, Fiji, Guam and the Commonwealth of the Northern Mariana Islands. Taiwan has been at the forefront of adopting the technologies that were implemented in Hawaii. The Taiwan Agricultural Research Institute has initiated a programme that includes 5\% of Taiwan's land, 172 
cooperating towns and villages and 149,713 ha involving 449 districts (McGregor, 2007). The Taiwan AWPM programme is now larger in scope than the Hawaii programme. Similarly, through a partnership between Hawaii and French Polynesia, introduction of $F$. arisanus into French Polynesia has resulted in $50 \%$ parasitism of fruit flies infesting a variety of tropical fruits, and reduced numbers of oriental fruit fly emerging from fruits by as much as $75 \%$ (Vargas et al., 2007a).

Establishment of $F$. arisanus is the most successful example of classical biological control of fruit flies in the Pacific area outside of the Hawaiian Islands, and serves as a model for introduction of the wasp into South America, Africa and China (PRC), where species of the B. dorsalis complex are established, in many cases without effective natural enemies. In summary, success of the fruit fly AWPM programme has not only helped other countries control their fruit fly problems but also helped protect US agriculture from fruit fly spread through a regional containment approach.

\section{Economic evaluation of costs and benefits of the AWPM programme}

An agricultural economist evaluated the costs and benefits of the Hawaii AWPM programme through interviews with stakeholders, farmer surveys and visits to demonstration sites and farms (McGregor, 2007). The consolidated estimated industry benefits of the AWPM programme are presented in Table 16.2 for production of cucurbits, tomato, citrus, persimmon, mango, dragon fruit, papaya and a possible new fruit. These benefits were extrapolated to the year 2014. Forecast benefits are projected to increase from US $\$ 2.6$ million in 2006 to US\$3.5 million in 2007. A cost-benefit analysis of the programme is summarized in Table 16.3. Further details on an economic analysis of the Hawaii AWPM programme can be found in McGregor (2007). The substantial non-industry benefits are not included in the formal benefit-cost analysis, but are discussed under sociological benefits.

\section{Sociological evaluation of the AWPM programme}

The strengthening of Hawaii's agricultural industry, weakened by the downsizing of the pineapple and sugarcane industries, has had a positive effect on the state economy. New jobs have been created in diversified agriculture and additional income generated as growers have expanded their acreage, sometimes reclaiming acres previously abandoned by growers unable to deal with fruit fly damage. The production of more high-value food crops has helped consumers in an island state that imports fruits and vegetables at considerable cost; many of these fruits and vegetables could be produced locally. If the AWPM programme helps increase local fruit production, consumers benefit from increased availability of quality fruit, lower fruit prices and low chemical residues in fruit. Ultimately, better fruit fly control could lead to new possibilities for export of high-value commodities.

Adoption of the AWPM programme has also benefited the unique, fragile Hawaiian environment by reducing the amount of organophosphate and carbamate 
Table 16.2. Consolidated quantifiable industry benefits from the Hawaii fruit fly AWPM programme (US $\$, 000)$.

\begin{tabular}{|c|c|c|c|c|c|c|c|c|c|c|c|c|c|c|c|c|}
\hline & 2000 & 2001 & 2002 & 2003 & 2004 & 2005 & 2006 & 2007 & 2008 & 2009 & 2010 & 2011 & 2012 & 2013 & 2014 & 2015 \\
\hline \multicolumn{17}{|c|}{ Benefits based on actual and forecast outputs } \\
\hline Cucubits & - & 200 & 400 & 600 & 1000 & 1000 & 1000 & 1100 & 1100 & 1200 & 1200 & 1300 & 1300 & 1300 & 1300 & 1300 \\
\hline Vine-ripened tomatoes & - & - & - & - & 200 & 500 & 700 & 800 & 900 & 1000 & 1000 & 1000 & 1000 & 1000 & 1000 & 1000 \\
\hline Citrus & - & - & - & 300 & 100 & 200 & 300 & 300 & 400 & 400 & 400 & 500 & 500 & 500 & 500 & 500 \\
\hline Persimmons & - & - & - & 200 & 200 & 300 & 300 & 300 & 400 & 400 & 400 & 500 & 500 & 500 & 500 & 500 \\
\hline Mango & - & - & - & 50 & 50 & 100 & 100 & 150 & 150 & 200 & 200 & 300 & 300 & 300 & 300 & 300 \\
\hline Dragon fruit & - & - & - & 30 & 40 & 50 & 60 & 70 & 80 & 90 & 100 & 110 & 110 & 110 & 110 & 110 \\
\hline Papaya & - & - & - & 30 & 40 & 50 & 70 & 50 & 1000 & 1500 & 2000 & 2000 & 2000 & 2000 & 2000 & 2000 \\
\hline $\begin{array}{l}\text { New 'highly susceptible' } \\
\text { fruit }\end{array}$ & - & - & - & - & 20 & 30 & 40 & 60 & 80 & 100 & 200 & 300 & 300 & 300 & 300 & 300 \\
\hline Subtotal & - & 200 & 400 & 1210 & 1650 & 2230 & 2570 & 3280 & 4110 & 4890 & 5500 & 6010 & 6010 & 6010 & 6010 & 6010 \\
\hline \multicolumn{17}{|c|}{ Benefits from 'likely' outputs over the next 5 years } \\
\hline Increased returns to papa & aya gr & owers & from he & larvestin & ng riper & fruit & & 200 & 300 & 400 & 500 & 600 & 600 & 600 & 600 & 600 \\
\hline Reduced quarantine costs $f$ & for $\mathrm{Pu}$ & na pap & aya grc & rowers & & & & & & 500 & 500 & 500 & 500 & 500 & 500 & 500 \\
\hline Reduced quarantine cost fo & or outs & shipme & nt of 'lo & ow risk' & product & & & & & 140 & 161 & 185 & 213 & 245 & 282 & 324 \\
\hline Subtotal & & & & & & & & 200 & 300 & 1040 & 1161 & 1285 & 1313 & 1345 & 1382 & 1424 \\
\hline \multicolumn{17}{|c|}{ Benefits from 'possible' outputs over the next 10 years } \\
\hline Papaya from Puna contro & ol area & witho & ut quar & rantine & treatme & & & & & & & 500 & 500 & 500 & 500 & 500 \\
\hline Outshipments of breadfru & & & & & & & & & & 300 & 315 & 331 & 347 & 365 & 383 & 402 \\
\hline Exports of high-value melon & ns to $J$ & Japan & & & & & & & & 300 & 330 & 363 & 399 & 439 & 483 & 531 \\
\hline Sub total & & & & & & & & & & 600 & 645 & 1194 & 1247 & 1304 & 1366 & 1433 \\
\hline Total consolidated benefits & - & 200 & 400 & 1210 & 1650 & 2230 & 2570 & 3480 & 4410 & 6530 & 7306 & 8489 & 8570 & 8659 & 8758 & 8867 \\
\hline
\end{tabular}


Table 16.3. A comparison of the consolidated programme benefits with costs $^{\mathrm{a}}(\mathrm{US} \$, 000)$.

\begin{tabular}{|c|c|c|c|c|c|c|c|c|c|c|c|c|c|c|c|}
\hline & 2000 & 2001 & 2002 & 2003 & 2004 & 2005 & 2006 & 2007 & 2008 & 2009 & 2010 & 2011 & 2012 & 20132014 & 2015 \\
\hline $\begin{array}{l}\text { Total } \\
\text { consolidated } \\
\text { benefit (B) }\end{array}$ & - & 200 & 400 & 1210 & 1650 & 2230 & 2570 & 3280 & 4110 & 4890 & 5500 & 6010 & 6010 & 60106010 & 6010 \\
\hline $\begin{array}{l}\text { Programme } \\
\text { costs }(C)\end{array}$ & 860 & 1300 & 1600 & 1960 & 1980 & 1970 & 1900 & 2000 & 800 & 750 & 750 & 750 & 250 & 250 & 250 \\
\hline$B-C$ & $(860)$ & (1100) & (1200) & $(750)$ & (330) & 260 & 670 & 1280 & 3310 & 4140 & 4750 & 5260 & 5760 & 57605760 & 5760 \\
\hline $\begin{array}{l}\text { Internal rate } \\
\text { of return } \\
\text { (IRR) (\%) }\end{array}$ & 28 & & & & & & & & & & & & & & \\
\hline $\begin{array}{l}\text { Programme } \\
\text { net present } \\
\text { value (NPV) }\end{array}$ & 34000 & & & & & & & & & & & & & & \\
\hline $\begin{array}{l}\text { (@ } 10 \% \text { rate } \\
\text { of interest) }\end{array}$ & & & & & & & & & & & & & & & \\
\hline
\end{tabular}

aUSDA-ARS Internal report by McGregor (2007). 
pesticides while still promoting an increase in agricultural production. Because of this programme, there has been tremendous support by growers and the public in utilizing technologies offered by the programme. Grower yields have increased, while organophosphate insecticide use has decreased. Tools are now legally available to control fruit fly and provide high-quality safe fruits and vegetables in Hawaii. Finally, the fortunes of expansion of diversified agriculture are closely linked to those of tourism; some 4.5 million people visit Hawaii annually. That creates a major market and the aircraft in which they arrive provide the freight capacity to outside markets at competitive rates. However, this relationship is not just one way. Diversified agriculture contributes significantly to the value of the tourism product: flowers, pineapples, tropical fruits, the open space created by farms that grow produce and an appealing environment are all part of the visitor experience (McGregor, 2007).

\section{Prospects for the long-term sustainability of the AWPM programme}

More than 2648 cooperating growers over five islands, representing more than 8449 ha (see Table 16.4), have joined the '1-2-3-4 programme'. They have been able to cut organophosphate pesticide use by $75-90 \%$. While using the AWPM programme that reduced environmental risks, growers have still cut fruit fly infestation by $30-40 \%$ to $<5 \%$ (Vargas et al., 2007b). Farmers have enthusiastically embraced the ' $1-2-3-4$ programme'.

Surveys conducted to test grower perceived knowledge of fruit fly control on the Big Island (Hawaii Island) indicated that $85 \%$ of growers had a good or fair understanding of the technology and fewer than $10 \%$ had poor or no understanding (McGregor, 2007). Technologies have been demonstrated that work, are user friendly and increase financial returns. To introduce the technology to farmers and home growers, monitoring traps with lures, male annihilation traps and GF-120 Fruit Fly Bait spray have been highly subsidized. Interviews with farmers indicate that they will have to meet these costs and are willing to do so after the ARS funding ends.

An 'all crops label' was obtained for GF-120 Fruit Fly Bait and an organically certified formulation, GF-120 NF Naturalyte Fruit Fly Bait, was marketed. Manufacturer's use permits (MUPs) were obtained in 2005 and 2006 for cue-lure and methyl eugenol, respectively. Major research and development efforts are presently under

Table 16.4. Total number of cooperators, number of farms and area impacted by the Hawaii Areawide Pest Management programme.

\begin{tabular}{lccc}
\hline Island & Total cooperators $(n)$ & Farms $(n)$ & Area (ha) \\
\hline Oahu & 436 & 108 & 2283 \\
Maui & 1270 & 62 & 2775 \\
Molokai & 31 & 26 & 141 \\
Kauai & 144 & 63 & 348 \\
Hawaii & 767 & 394 & 2902 \\
Statewide & 2648 & 653 & 8449 \\
\hline
\end{tabular}


way by ARS, UH and industry (FarmaTech, Sentry, BASF and ISCA Technologies) to provide methyl eugenol and cue-lure 'end products' for use in male annihilation treatments when USDA-ARS funding of the programme ends.

Registration of male annihilation end products is critical for programme sustainability. For smaller farmers to continue with male annihilation strategies, these lures must be available in their local farm supply store. It is hoped that the registration of methyl eugenol and cue-lure end products for fruit fly control will be approved by EPA in 2007. It would be ideal if these products could be demonstrated on local farms while the AWPM programme is still being funded.

The ongoing research and extension and public education programme will also need to be continued after programme funding ends, to consolidate and expand the benefits that have been achieved thus far. The cost of the AWPM programme extension and education components have been relatively modest compared with the benefits that have been achieved. The University of Hawaii has conducted an effective extension effort on Oahu, Maui, Kauai and Molokai, channelled through the Cooperative Extension Service. The extension programme on the Big Island has also been effective, where ARS has taken the lead. To ensure sustainability of the AWPM programme, particularly among smaller farmers and new cooperators, there needs to be a future commitment to continued research on these pests, as well as extension support for training and distribution of information on control technologies and products.

The small-scale SIT releases for melon fly, medfly and oriental fruit fly have been effective but, without federal support and a rearing facility, this technology will not be sustainable. Similarly, classical releases of parasitoids were shown to be cost-effective where natural enemies were non-existent, but augmentative releases, although promising, are not a proven technology and cannot be sustained without a rearing facility.

Adherence to the '1-2-3-4 programme' at the four demonstration sites for the three species of fruit fly was shown to be effective in its own right in suppressing fruit flies below economic thresholds. However, the level of suppression will not be as great as with sterile flies. From all accounts the cost of a '1-2-3-4 programme' is far lower without the sterile flies and parasitoids. Furthermore, the responsibility for meeting these costs lies with the farmer. With the farmers controlling their own destiny, greater sustainability can be expected than with programmes relying on continuous public expenditure.

\section{Summary and Future Directions}

In summary, ensuring adoption of the programme by Hawaiian farmers required far more than just research and development of the technology. Partnerships were created with the Hawaii Department of Agriculture (HDOA) and the University of Hawaii $(\mathbf{U H})$. ARS researchers and $\mathrm{UH}$ personnel and extension agents worked tirelessly with growers to help them take control of the technology package. HDOA provided the impetus to register control products. Other partners were then enlisted to enhance cooperation and give the programme the best chance of success, including 
the USDA, APHIS, the IR-4 pesticide programme, the US Environmental Protection Agency, private industry (including Dow AgroSciences Inc., BASF, FarmaTech International, Sentry and ISCA Technologies) and local community action groups.

At the heart of the programme, however, were the Hawaiian farmers and gardeners who have participated as cooperators in demonstrating the benefits of the programme and then spread the word to others. The AWPM team had to overcome growers' reluctance to put themselves at economic risk by trying technologies they perceived as experimental. The team also had to overcome growers' disappointment with previous, unsuccessful eradication attempts during the past 25 years.

Extension agents, ARS researchers, UH researchers and HDOA officials met with grower groups to explain the idea and procedures. Extensive educational and 'how-to-do' materials have been created, including videos, a web site, public service announcements, pamphlets, handouts and posters to help growers and gardeners adopt the programme. But personal communication with growers was the real basis for the successful adoption of the programme. Growers were empowered to make informed decisions about adopting and continuing the programme.

Future plans include: (i) expansion of the oriental fruit fly programme to include other crops besides papaya; (ii) training of avocado and papaya growers in Puna and Kona in the '1-2-3-4 programme' approach for fruit fly suppression; (iii) demonstration of the effectiveness of the '1-2-3-4 programme' for control of B. latifrons; (iv) continued research to address problems which inhibit implementation of the AWPM programme, such as non-target and economic issues; (v) expansion into other agricultural areas of the state not part of the present AWPM programme; and (vi) promotion of sustainability through registration of methyl eugenol and cue-lure end products with the EPA.

\section{Acknowledgements}

The Hawaii Fruit Fly AWPM programme is a USDA-Agricultural Research Servicefunded partnership with the University of Hawaii Cooperative Extension Service and Hawaii State Department of Agriculture. Principal investigators (USDA, ARS, USPBARC) on the project included Roger Vargas, Eric Jang, Don McInnis, Grant McQuate, Ernest Harris and Stella Chang. The original project proposal was written and submitted by Roger Vargas and Mary Purcell in 1997, revised by the principal investigators listed above and funded in 1999. The authors especially acknowledge the help of Kim Kaplan (ARS, USDA, information staff), Mike Klungness, Jill Grotkin, Ferol White and Nancy Chaney (ARS, USDA, PBARC, Hilo) with this manuscript. Finally, we would like to recognize the past and present employees of ARS, UH, HDOA and APHIS who worked tirelessly to make this programme a success.

\section{References}

Back, E.A. and Pemberton, C.E. (1917) The melon fly in Hawaii. USDA Bulletin 491. 
Cunningham, R.T. and Suda, D.Y. (1985) Male annihilation of the oriental fruit fly (Diptera: Tephritidae): a new thickener and extender for methyl eugenol formulations. Journal of Economic Entomology 78, 503-504.

Cunningham, R.T. and Suda, D.Y. (1986) Male annihilation through mass-trapping of male flies with methyl eugenol to reduce infestation of oriental fruit fly (Diptera: Tephritidae) larvae in papaya. Journal of Economic Entomology 79, 1580-1582.

Cunningham, R.T., Chambers, D.L. and Forbes, A.G. (1975) Oriental fruit fly: thickened formulations of methyl eugenol in spot applications for male annihilation. Foumal of Economic Entomology 68, 861-863.

Cunningham, R.T., Routhier, W., Harris, E.J, Cunningham, G., Tanaka, N., Johnston, L., Edwards, W., Rosander, R. and. Vettel, J. (1980) A case study: eradication of medfly by sterile-male release. Citrograph 65, 63-69.

DeBach, P. and Rosen, D. (1991) Biological Control by Natural Enemies. Cambridge University Press, Cambridge, UK.

Dominguez, V.M., Leyva, J.L., Moreno, D.S., Trujillo, F.J., Alatorre, R. and Enrique Becerril, A. (2003) Toxicidad sobre Apis mellifera de cebos empleados en el combate de moscas de la fruta. Manejo Integrado de Plagas y Agroecologia 69, 66-72.

DowElanco (1994) Spinosad Technical Guide. DowElanco, Indianapolis, Indiana.

Dowell, R.V. (1997) Laboratory toxicity of a photo activated dye mixture to six species of beneficial insects. Fournal of Applied Entomology 121, 271-274.

Drew, R.A.I., Tsuruta, K. and White, I.M. (2005) A new species of pest fruit fly (Diptera: Tephritidae: Dacinae) from Sri Lanka and Africa. African Entomology 13, 149-154.

Ebeling, W., Nishida, T. and Bess, H.A. (1953) Field experiments on the control of melon fly, Dacus cucurbitae. Hilgardia 31, 563-591.

FAO/IAEA (2005) Alert notice USDA-APHIS: elevated risk of peach fruit fly (Bactrocera zonata) from Egypt. Insect Pest Control Newsletter 65, 18.

Faust, R.M. (2004) Local research, but everyone's watching. (Forum, Hawaii Areawide Fruit Fly Control Program, Pacific Basin Agricultural Research Center). Agricultural Research 1 February.

Haramoto, F.H. and Bess, H.A. (1970) Recent studies on the abundance of the oriental and Mediterranean fruit flies and the status of their parasites. Proceedings of the Hawaiian Entomological Society 20, 551-566.

Hardy, D.E. (1979) Economic fruit flies of the South Pacific Region. Book Review. Pacific Insects 20, 429-432.

Harris, E.J., Cunningham, R.T., Tanaka, N., Ohinata, K. and. Shroeder, W.J. (1986) Development of the sterile-insect technique on the island of Lanai, Hawaii, for suppression of the Mediterranean fruit fly. Proceedings of the Hawaiian Entomological Society $26,77-88$.

Harris, E.J., Bautista, R.C. and Spencer, J.P. (2000) Utilization of the egg-larval parasitoid, Fopius (Biosteres) arisanus, for augmentative biological control of fruit flies. In: Tan, K.H. (ed.) Areawide Control of Fruit Flies and Other Insect Pests. Penerbit Univesiti Sains Malaysia, Pulau Pinang, Malaysia, pp. 725-732.

Jang, E.B. (2003) A prescription against fruit flies. Agriculture Hawaii 4, 6-7.

Jang, E.B. and Moffitt, H.F. (1994) Systems approaches to achieving quarantine security. In: Sharp, J.L. and Hallman, G.J. (eds) Quarantine for Pests of Food Plants. Westview Press, Boulder, Colorado, pp. 225-239.

Keiser, I. (1968) Residual effectiveness of foliar sprays against the Oriental fruit fly, melon fly, and the Mediterranean fruit fly. Fournal of Economic Entomology 61, 438-443.

Kido, M.H., Asquith, A. and Vargas, R.I. (1996) Nontarget insect attraction to methyl eugenol used in male annihilation of the oriental fruit fly (Diptera: Tephritidae) in riparian Hawaiian stream habitat. Environmental Entomology 25, 1279-1289. 
Klungness, L.M., Jang, E.B., Mau, R.F.L, Vargas, R.I., Sugano J.S. and Fujitani, E. (2005) New sanitation techniques for controlling tephritid fruit flies (Diptera: Tephritidae) in Hawaii. Fournal of Applied Sciences and Environmental Management 9, 4-14.

Knipling, E.F. (1995) Principles of Insect Parasitism Analyzed from New Perspectives. Practical Implications for Regulating Insect Populations by Biological Means. Handbook No. 693, United States Department of Agriculture, Pittsburgh, Pennsylvania.

Koyama, J. (1996) Eradication of the melon fly, Bactrocera cucurbitae by the sterile insect technique in Japan. Proceedings of IAEA Training Course on the Use of Sterile Insect and Related Techniques for the Areawide Management of Insect Pests, Gainesville, Florida, 8 May-19 June 1996.

Koyama, J., Teruya, T. and Tanaka, K. (1984) Eradication of the oriental fruit fly (Diptera: Tephritidae) from the Okinawa Islands by a male annihilation method. Fournal of Economic Entomology 77, 468-472.

Mau, R.F.L., Sugano, J.S and Jang, E. (2003a) Farmer education and organization in the Hawaii areawide fruit fly pest management program. In: Inamine, K. (ed.) Recent Trends on Sterile Insect Technique and Areazide Integrated Pest Management: Economic Feasibility, Control Projects, Farmer Organization and Dorsalis Complex Control Study. Research Institute for Subtropics, Okinawa, Japan, pp. 47-57.

Mau, R.F.L., Sugano, J.S. and Hamasaki, D. (2003b) Prescription for Fruit Fly Suppression (videotape). Video Series No. 164, College of Tropical Agriculture and Human Resources, Honolulu, Hawaii.

Mau, R.F.L., Jang, E.B. and Vargas, R.I. (2007) The Hawaii fruit fly area-wide fruit fly pest management programme: influence of partnership and a good education programme. In: Vreysen, M.J.B., Robinson, A.S. and Hendrichs, J. (eds) Area-wide Control of Insect Pests: from Research to Field Implementation. Springer, Dordrecht, Netherlands. (In press).

McGregor, A.M. (2007) An Economic Evaluation of the Hawaii Fruit Fly Area-wide Pest Management Program. Draft final report, a study funded by the College of Tropical Agriculture and Human Resources, University of Hawaii. Honolulu, Hawaii.

McInnis, D.O., Tam, S., Grace, C. and Miyashita, D. (1994) Population suppression and sterility rates induced by variable sex ratio, sterile insect releases of Ceratitis capitata (Diptera: Tephritidae) in Hawaii. Annals of the Entomological Society of America 87, 231-240.

McInnis, D.O., Shelly, T.E. and Mau, R.F.L. (2006) All male strains and chemical stimulants: two ways to boost sterile males in SIT programs. In: Ku, T.Y. (ed.) Proceedings of International Symposium on Area-wide Management of Insect Pests, Naha, Okinawa, Japan, 8-11 October 2006, pp. 53-62.

McInnis, D., Leblanc, L. and Mau, R.F.L. (2007) Development and field release of q genetic sexing strain of the melon fly, Bactrocera cucurbitae, in Hawaii. Proceedings of the Hawaiian Entomological Society (in press).

McQuate, G.T., Cunningham, R.T., Peck, S.L. and Moore, P.H. (1999) Suppressing oriental fruit fly populations with phloxine B-protein bait sprays. Pesticide Science 55, 566-614.

Metcalf, R.L. (1990) Chemical ecology of Dacinae fruit flies (Diptera: Tephritidae). Annals of the Entomological Society of America 83, 1017-1030.

Metcalf, R.L. and Metcalf, E.R. (1992) Fruit flies of the family Tephritidae. In: Metcalf, R.L. and Metcalf, E.R. (eds) Plant Kairomones in Insect Ecology and Control. Routledge, Chapman \& Hall Inc., New York, pp. 109-152.

Moreno, D.S. and Managan, R.L. (1995) Responses of the Mexican fruit fly (Diptera: Tephritidae) to two hydrolyzed proteins and incorporation of phloxine $\mathrm{B}$ to kill adults. In: Heitz, J.R. and Downum, K. (eds) Light Activated Pest Control. ACS Symposium Series 616, American Chemical Society, Washington, DC, pp. 257-259.

Newell, I.M. and Haramoto, F.H. (1968) Biotic factors influencing populations of Dacus dorsalis in Hawaii. Proceedings of the Hawaiian Entomological Society 20, 81-139. 
Nishida, T. (1953) Ecological study of the melon fly, Dacus cucurbitae Coquillett, in the Hawaiian Islands. PhD dissertation, University of California, Berkeley, California.

Nishida, T. and Bess, H.A. (1950) Applied ecology in melon fly control. Foumal of Economic Entomology 43, 877-883.

Nishida, T., Bess, H.A. and Ota, A. (1957) Comparative effectiveness of Malathion and Malathionyeast Hydrolysate bait sprays for control of melon fly. Joumal of Economic Entomology 50, $680-684$.

Peck, S.L. and McQuate, G.T. (2000) Field tests of environmentally friendly malathion replacements to suppress wild Mediterranean fruit fly (Diptera: Tephritidae) populations. Joumal of Economic Entomology 93, 280-289.

Prokopy, R.J., Papaj, D.R., Hendrichs, J. and Wong, T.T.Y. (1992) Behavioral responses of Ceratitis capitata flies to bait spray droplets and natural food. Entomologia Experimentalis et Applicata 64, 247-257.

Prokopy, R.J., Miller, N.W., Pinero, J.G., Barry, J.D., Tran, L.C., Oride, L.K. and Vargas, R.I. (2003) Effectiveness of GF-120 fruit fly bait spray applied to border area plants for control of melon flies (Diptera: Tephritidae). Foumal of Economic Entomology 96, 1485-1493.

Prokopy, R.J., Miller, N.M., Pinero, J.C., Oride, L., Ghaney, N., Revis, H.C. and Vargas, R.I. (2004) How effective is GF-120 fruit fly bait spray applied to border area sorghum plants for control of melon flies (Diptera: Tephritidae)? Florida Entomologist 87, 354-360.

Purcell, M.F. and Messing, R.H. (1996) Effect of ripening fruit in three vegetable crops on abundance of augmentatively released Psyttalia fletcheri: improved sampling and release methods. Entomophaga 41, 105-115.

Purcell, M.F., Jackson, C.G., Long, J.P. and Batchelor, M.A. (1994a) Influence of guava ripening on parasitism of the oriental fruit fly, Bactrocera dorsalis (Hendel) (Diptera: Tephritidae) by Diachasmimorpha longicaudata and Psyttalia fletcheri (Hym: Braconidae) and other parasitoids. Biological Control Theory and Application 4, 396- 403.

Purcell, M.F., Daniels, D.M., Messing, L.M., Whitehand, L.C. and Whitehand, R.H. (1994b) Improvement of quality control methods for augmentative releases of the fruit fly parasitoids Diachasmimorpha longicaudata and Psyttalia fletcheri (Hym.: Braconidae). Biocontrol Science and Technology 4, 155-166.

Rendon, P., McInnis, D., Lance, D. and Stewart, J. (2004) Medfly (Diptera: Tephritidae) genetic sexing: large-scale field comparison of males-only and bisexual sterile fly releases in Guatemala. Journal of Economic Entomology 97, 1547-1553.

Roessler, Y. (1989) Insecticidal bait and cover sprays. In: Robinson, A.S. and Hooper, G. (eds) Fruit Flies. Their Biology, Natural Enemies and Control. Elsevier, Amsterdam, vol. 3A, pp. 329-335.

Rousse, P., Harris, E.J. and Quilici, S. (2005) Fopius arisanus, an egg-pupal parasitoid of Tephritidae. Overview. Biocontrol News and Information $26,59 \mathrm{~N}-69 \mathrm{~N}$.

Stark, J.D., Vargas, R.I. and Miller, N.W. (2004) Toxicity of spinosad in protein bait to three economically important tephritid fruit fly species (Diptera: Tephritidae) and their parasitoids (Hymenoptera: Braconidae). Fournal of Economic Entomology 97, 91 1--915.

Steiner, L.F., Rohwer, G.G., Ayers, E.L. and Christenson, L.D. (1961) The role of attractants in the recent Mediterranean fruit fly eradication programme in Florida. Foumal of Economic Entomology 54, 30-35.

Steiner, L.F., Mitchell, W.C., Harris, E.J., Kozuma, T.T. and Fujimoto, M.S. (1965) Oriental fruit fly eradication by male annihilation. Foumal of Economic Entomology 58, 961-964.

Steiner, L.F., Hart, W.G., Harris, E.J., Cunningham, R.T., Ohinata, K. and Kamakahi, D.C. (1970) Eradication of the oriental fruit fly from the Mariana Islands by the methods of male annihilation and sterile insect release. Fournal of Economic Entomology 63, 131-135.

Uchida, G.K., McInnis, D.O., Vargas, R.I., Kumashiro, B.R. and Jang, E.B. (2004) Non-target arthropods captured in cue-lure baited bucket traps at area-wide pest management 
implementation sites in Kamuela and Kula, Hawaiian Islands. Proceedings of the Hawaiian Entomological Society 36, 135-143.

Uchida, G.K., Mackey, B.E., Vargas, R.I., Beardsley, J.W., Hardy, D.E., Goff, M.L. and Stark, J.D. (2007) Response of nontarget insects to methyl eugenol, cue-lure, trimedlure, and protein bait traps in the Hawaiian Islands. Proceedings of the Hawaïan Entomological Society $38,61-72$.

Vargas, R.I. (1996) Suppression of Mediterranean fruit fly populations with SIT in two habitats: a coffee agroecosystem with a braconid parasitoid and a forest with scattered patches of coffee in the understory. Proceedings of the Fourth International Symposium on Fruit Flies of Economic Importance, Sand Key, Florida.

Vargas, R.I. and Nishida, T. (1985) Survey for Dacus latifrons (Diptera: Tephritiade). Fournal of Economic Entomology 78, 1311-1344.

Vargas, R.I., and Prokopy, R.J. (2007) Attraction and feeding responses of melon flies and oriental fruit flies (Diptera: Tephritidae) to various protein baits with and without toxicants. Proceedings of the Hawaiian Entomological Society 38, 49-60.

Vargas, R.I., Nishida, T. and Beardsley, J.W. (1983) Distribution and abundance of Dacus dorsalis (Diptera: Tephritidae) in native and exotic forest areas on Kauai. Journal of Environmental Entomology 12, 1185-1189.

Vargas, R.I., Stark, J.D., Uchida, G.K. and Purcell, M. (1993) Opiine parasitoids (Hymenoptera: Braconidae) of Oriental fruit fly (Diptera: Tephritidae) on Kauai Island, Hawaii: islandwide relative abundance and parasitism rates in wild and orchard guava habitats. Environmental Entomology 22, 246-253.

Vargas, R.I., Walsh, W.A., Hsu, G.L., Spencer, J., Mackey, B. and Whitehand, L. (1994) Effects of sterile Mediterranean fruit fly (Diptera: Tephritidae) releases on the target species, a nontarget tephritid, and a braconid parasitoid (Hymenoptera: Braconidae) in commercial coffee fields. Fournal of Economic Entomology 87, 653-660.

Vargas, R.I., Walsh, W.A., Hsu, C.L., Whitehand, L. and Spencer, J.P. (1995) Aerial releases of sterile Mediterranean fruit fly (Diptera: Tephritidae) by helicopter: dispersal, recovery, and suppression. Journal of Economic Entomology 88, 1279-1287.

Vargas, R.I., Stark, J.D., Kido, M.H., Ketter, H. and Whitehand, L.C. (2000) Methyl eugenol and cue-lure traps for suppression of male oriental fruit flies and melon flies (Diptera: Tephritidae) in Hawaii: effects of lure mixtures and weathering. Fournal of Economic Entomology 93, 81-87.

Vargas, R.I., Peck, S.L., McQuate, G.T., Jackson, C.G., Stark, J.D. and Armstrong, J.W. (2001) Potential for areawide integrated management of Mediterranean fruit fly (Diptera: Tephritidae) with a braconid parasitoid and a novel bait spray. Fournal of Economic Entomology 94, 817-825.

Vargas, R.I., Miller, N.W. and Prokopy, R.J. (2002) Attraction and feeding responses of Mediterranean fruit fly and a natural enemy to protein baits laced with two novel toxins, phloxine B and spinosad. Entomologia Experimentalis et Applicata 102, 273-282.

Vargas, R.I., Miller, N.W. and Stark, J.D. (2003a) Field trials of spinosad as a replacement for Naled, DDVP, and malathion in methyl eugenol and cue-lure bucket traps to attract and kill male oriental fruit flies and melon flies (Diptera: Tephritidae) in Hawaii. fournal of Economic Entomology 96, 1780-1785.

Vargas, R.I., Jang, E.B. and Klungness, L.M. (2003b) Areawide pest management of fruit flies in Hawaiian fruits and vegetables. In: Inamine, K. (ed.) Recent Trends on Sterile Insect Technique and Areazide Integrated Pest Management. Research Institute for Subtropics, Okinawa, Japan, pp. 37-46.

Vargas, R.I., Long, J., Miller, N.W., Delate, K., Jackson, C.G., Uchida, G.K., Bautista, R.C. and Harris, E.J. (2004) Releases of Psyttalia fletcheri (Hymenoptera: Braconidae) and sterile flies to suppress melon fly (Diptera: Tephritidae) in Hawaii. Fournal of Economic Entomology 97, 1531-1539. 
Vargas, R.I., Leblanc, L., Putoa, R. and Eitam, A. (2007a) Impact of introduction of Bactrocera dorsalis (Diptera: Tephritidae) and classical biological control releases of Fopius arisanus (Hymenoptera: Braconidae) on economically important fruit flies in French Polynesia. Foumal of Economic Entomology 100, 670-679.

Vargas, R.I., Mau, R.F.L. and Jang, E.B. (2007b) The Hawaii fruit fly area-wide pest management programme: accomplishments and future directions. Proceedings of the Hawaiian Entomological Society (in press).

Weems, H.V. (1964) Melon fly (Dacus cucurbitae Coquillett) (Diptera: Tephritidae). Entomology Circular, Division of Plant Industry, Florida Department of Agriculture and Consumer Services 21, 1-2.

White, I.M. and Elson-Harris, M.M. (1992) Fruit Flies of Economic Significance: their Identification and Bionomics. CABI, Wallingford, UK.

Wong, T.T.Y., Ramadan, M.M., McInnis, D.O., Mochizuki, N., Nishimoto, J.I. and Herr, J.C. (1991) Augmentative releases of Diachasmimorpha tryoni (Hymenoptera: Braconidae) to suppress a Mediterranean fruit fly (Diptera: Tephritidae) population in Kula, Maui, Hawaii. Biological Control 1, 2-7.

Wong, T.T.Y., Ramadan M.M., Herr, M.M. and McInnis, D.O. (1992) Suppression of a Mediterranean fruit fly (Diptera: Tephritidae) population with concurrent parasitoid and sterile fly release in Kula, Maui, Hawaii. Journal of Economic Entomology 85, 1671-1681.

Yokoyama, V.Y. and Miller, G.T. (2004) Quarantine strategies for olive fruit fly (Diptera: Tephritidae): low-temperature storage, brine, and host. Journal of Economic Entomology 97, 1249-1253. 